\title{
An Exact Method to Determine the Conductivity of Aqueous Solutions in Acid-Base Titrations
}

\author{
Norma Rodríguez-Laguna, ${ }^{1}$ Alberto Rojas-Hernández, ${ }^{1}$ María Teresa Ramírez-Silva, \\ Lucero Hernández-García, ${ }^{1}$ and Mario Romero-Romo ${ }^{2}$ \\ ${ }^{1}$ Laboratorio R-105/R-107, Área de Química Analítica, Departamento de Química, División de Ciencias Básicas e Ingeniería, \\ Universidad Autónoma Metropolitana-Iztapalapa, Avenida San Rafael Atlixco 186, Colonia Vicentina, 09340 México, DF, Mexico \\ ${ }^{2}$ Área Ingeniería de Materiales, Departamento de Materiales, División de Ciencias Básicas e Ingeniería, \\ Universidad Autónoma Metropolitana-Azcapotzalco, Avenida San Pablo 180, Colonia Reynosa-Tamaulipas, \\ 02200 México, DF, Mexico
}

Correspondence should be addressed to Alberto Rojas-Hernández; suemi918@xanum.uam.mx

Received 6 November 2014; Accepted 8 January 2015

Academic Editor: Patricia Valentao

Copyright ( 2015 Norma Rodríguez-Laguna et al. This is an open access article distributed under the Creative Commons Attribution License, which permits unrestricted use, distribution, and reproduction in any medium, provided the original work is properly cited.

\begin{abstract}
Several works in the literature show that it is possible to establish the analytic equations to estimate the volume $V$ of a strong base or a strong acid ( $V_{b}$ and $V_{a}$, resp.) being added to a solution of a substance or a mix of substances during an acid-base titration, as well as the equations to estimate the first derivative of the titration plot $d \mathrm{pH} / d V$, and algebraic expressions to determine the buffer $(\beta)$ capacity with dilution $\left(\beta_{\mathrm{dil}}\right)$. This treatment allows establishing the conditions of thermodynamic equilibria for all species within a system containing a mix of species from one or from various polyacid systems. The present work shows that it is possible to determine exactly the electric conductivity of aqueous solutions for these Brønsted acid-base titrations, because the functional relation between this property and the composition of the system in equilibrium is well known; this is achieved using the equivalent conductivity $\left(\lambda_{i}\right)$ values of each of the ions present in a given system. The model employed for the present work confirms the experimental outcomes with the $\mathrm{H}_{2} \mathrm{SO}_{4}, \mathrm{~B}(\mathrm{OH})_{3}, \mathrm{CH}_{3} \mathrm{COOH}$, and $\mathrm{H}_{3} \mathrm{PO}_{4}$ aqueous solutions' titration.
\end{abstract}

\section{Introduction}

It is well known that electrolyte solutions frequently obey Ohm's Law, where the conductance ( $L$, reciprocal of the resistance $(R))$ is the electrical property of the solution that establishes readily the inherent facility with which it transports electric charges, under the influence of an electric field. The conductance depends on the temperature, the solution's composition, and the geometry of the electric field applied in reference to the solution. However, the electrical conductivity $(\kappa)$ of the system can also be defined, which does not depend on the said geometry [1-4].

The functional relation between the electrical conductivity and the conductance is established with reference to a geometric empirical factor $(H$, known as cell constant with units of the length reciprocal), in agreement with the following:

$$
\kappa=L H .
$$

On another respect, Kolhrausch's law, or law of ions' independent migration, correlates the electric conductivity with the solution composition, this being a linear law of concentrations, as shown by the following:

$$
\kappa=\sum_{i=1}^{n}\left|z_{X_{i}}\right| \lambda_{X_{i}}^{o}\left[X_{i}\right]
$$

where $\left|z_{X_{i}}\right|$ is the absolute value of the charge, $\lambda_{X_{i}}^{o}$ is the limiting equivalent conductivity (at infinite dilution), and $\left[X_{i}\right]$ is the molar concentration of the $i$ th ion, whereas the sum concerns all ions comprised. 
During the course of volume titration, changes occur on the number and type of ions present in the solution to be titrated, also with an increase of the overall solution volume. Thus, in order to represent the conductometry plots obtained from the said titrations, it is recommended to define the corrected electric conductivity through dilution $\left(\kappa_{\text {corr }}\right)$ for the measured value of the conductivity [4-7] in agreement with the following expression:

$$
\kappa_{\text {corr }}=\kappa \frac{\left(V_{o}+V\right)}{V_{o}} .
$$

$V_{o}$ is the initial volume of the titrated system and $V$ the titrant added volume.

The literature states that there are linear relations (per segments) of the $\kappa_{\text {corr }}$ with the titrant's volume, with different slopes at each side of any of the equivalence points, provided the titrating reactions are quantitative. The plots of $\kappa_{\text {corr }}=$ $f(V)$ deviate from linearity in the vicinity of the equivalence point when the reactions are less quantitative, which generally occurs when the solution becomes more diluted. Thus, the linear behaviors of the said plots are observed only at points far from the equivalence points [5-7]. Therefore, in systems where there are several titration reactions with relatively small slope changes it becomes difficult to decide what points can be considered within the linear trends of the plot.

Several works, reported in the literature, describe robust models to predict and interpret $\mathrm{pH}$ plots as a function of the titrant added, obtained during acid-base titrations. Among them, documents can be found that describe the functions where the titrant volume $(V)$ is resolved as a function of $\mathrm{pH}$ [8-12] up to more extensive works, such as that excellent revision by Asuero and Michalowski [13] that, apart from describing much more robust models to predict acid-base titration plots, describe other functions related with them, such as the $\mathrm{pH}$ derivatives with respect to $V$ or the buffer $(\beta)$ capacity of various systems.

In previous works we have presented explicit titrant volume expressions as a function of $\mathrm{pH}(V=f(\mathrm{pH}))$ for titrations of mixtures of species of the same proton polydonor system with a strong acid or base $[14,15]$. Also, these papers presented the exact equations for the $\mathrm{pH}$ derivative with respect to the $V$ and the buffer capacity with dilution $\left(\beta_{\text {dil }}\right)$ of those systems. In order to construct the plots obtained from the said equations, several spread sheets were built at Excel, Microsoft.

The objective of this work is to present a robust model that allows estimation of the conductometric titration plots in complicated mixtures, without the need to find the linear regions of the plots before and after each equivalence point, with the aim to define exactly and precisely the volume of each of those equivalence points.

Thus, the present paper shows how to apply advantageously these equations in order to build the conductometric plots $(\kappa=g(V))$ without approximations, using nonlinear functions that remain implicit over the spread sheets used to build the graphs of the acid-base titrations.

\section{Materials and Methods}

\subsection{Methodology}

2.1.1. Acid-Base Titrations of Mixtures of Species of the Same Proton Polydonor System: $H_{n} L / H_{(n-1)} L / \cdots / H_{j} L / \cdots / H L /$ $L / H^{+}$. In order to establish a model that allows determination of the system's equilibrium conditions during an acidbase titration and to estimate the $\mathrm{pH}$-metric plot, namely, $\mathrm{pH}=f(V)$, it seems adequate to solve the $\mathrm{pH}$ as a function of the volume (as established in the previous function), using the necessary equations to express the equilibrium condition in terms of the two variables. However, apart from the titrations of strong acid with strong base or those of strong base with strong acid, the equation to solve, at least, is a 3rd order polynomial equation [16].

Further, the equation is linear with respect to the volume even in the case of mixtures of species that belong to the same protons polydonor system, namely, $H_{n} L / H_{(n-1)} L / \cdots /$ $H_{j} L / \cdots / H L / L / \mathrm{H}^{+}$. In order to simplify the nomenclature, note that, in the previous notation, the electric charges of component $L$ species have been omitted.

A common way to obtain the equation from which the titrant's volume is solved results from establishing the electroneutrality equation in the system and substituting in it the equilibrium concentrations of the ions comprised.

Then a robust model is obtained for estimations when solving the strong base $\left(V_{b}\right)$ and strong acid $\left(V_{a}\right)$ volumes that were added in an acid-base titration as a function of $\mathrm{pH}$ $[8,13,14]$.

This way, the added titrant's volume is a function of $\mathrm{pH}$ as variable as well as other parameters, namely:

(1) the initial volumes $\left(V_{o j}\right)$ of the solutions that contain each of the species of the polydonor system for titration $\left(H_{j} L\right)$, considering also its counterions (when appropriate), that after mixing lead to the initial volume of the mix to be titrated $\left(V_{o}=\sum_{j=0}^{n} V_{o j}\right)$,

(2) the electric charges of the species of the polydonor system and its counterions $(j-a)$, where $a$ represents the absolute value of the electric charge of the base of the system, $L$,

(3) the equilibrium concentrations of the hydronium ion $\left(\left[\mathrm{H}^{+}\right]=10^{-\mathrm{pH}}\right)$ and of the hydroxide ion $\left(\left[\mathrm{OH}^{-}\right]=K_{w} /\left[\mathrm{H}^{+}\right]=10^{(\mathrm{pH}-\mathrm{pK} w)}\right.$, where $K_{w}$ is the autoprotolysis constant of the solvent),

(4) the initial molarities of the species $\left(C_{o j}\right)$, that because of the balance of the $L$ component lead to $\left(V_{o} C_{o}=\right.$ $\left.\sum_{j=0}^{n} V_{o j} C_{o j}\right)$

(5) the molar fractions in the equilibrium $\left(f_{j}\right)$, defined in accordance with the mass balance for the $L$ component. Generally, these molar fractions are graphically represented through a distribution diagram because 
they are functions that depend only on the dissolution's $\mathrm{pH}$ :

$$
\begin{aligned}
f_{j} & =f_{H_{j} L}=\frac{\left[H_{j} L\right]}{[L]_{\text {total }}}=\frac{1}{\sum_{j=0}^{n}\left(\beta_{j}[H]^{j}\right)} \\
& =\frac{1}{\sum_{j=0}^{n}\left(10^{\left(\log \beta_{j}-j \mathrm{pH}\right)}\right)},
\end{aligned}
$$

where $\beta_{o} \equiv 1$ and $\beta_{j}$ are the global formation constants of the $(n+1)$ species of $L$ in the system, because $j \in\{1,2, \ldots, n\}$.

Therefore, if a volume $V_{o}$ of a mixture of species of the same proton polydonor system $\left(\underline{H}_{n} \underline{L} / H_{(n-1)} L / \cdots / H_{j} L / \cdots /\right.$ $\left.H L / L / \mathrm{H}^{+}\right)$with overall molarity $[L]_{\text {total }}=C_{o}$, is titrated with a strong base or a strong acid of molarity $C_{b}$ or $C_{a}$, respectively; it can be shown that the added titrant volume for titration with a strong base $\left(V_{b}\right)$ gives rise to (5), whereas for titration with a strong acid $\left(V_{a}\right)$ it leads to (6) as follows:

$$
\begin{gathered}
V_{b}=\left(-V_{o} C_{o}\left[\sum_{j=0}^{n}\left\{(j-a) f_{j}\right\}\right]+\sum_{j=0}^{n}\left\{(j-a)\left(V_{o j} C_{o j}\right)\right\}\right. \\
\left.-V_{o}\left(\left[\mathrm{H}^{+}\right]-\frac{K_{w}}{\left[\mathrm{H}^{+}\right]}\right)\right)\left(C_{b}+\left[\mathrm{H}^{+}\right]-\frac{K_{w}}{\left[\mathrm{H}^{+}\right]}\right)^{-1}, \\
V_{a}=\left(V_{o} C_{o}\left[\sum_{j=0}^{n}\left\{(j-a) f_{j}\right\}\right]-\sum_{j=0}^{n}\left\{(j-a)\left(V_{o j} C_{o j}\right)\right\}\right. \\
\left.+V_{o}\left(\left[\mathrm{H}^{+}\right]-\frac{K_{w}}{\left[\mathrm{H}^{+}\right]}\right)\right)\left(C_{a}-\left[\mathrm{H}^{+}\right]+\frac{K_{w}}{\left[\mathrm{H}^{+}\right]}\right)^{-1} .
\end{gathered}
$$

Now, for the same titration and considering (2) it is possible to deduce (7) to estimate the conductivity at every $\mathrm{pH}$.

In (7), $Q_{T}$ represents the titrant counterion and $Q_{j}$ represents the counterion of the species $H_{j} L$, while $\lambda_{X}$ represents the equivalent conductivity of the ion $X$ away from the limiting conditions that, theoretically, should be smaller than or equal to the $\lambda_{X}^{o}[2]$ :

$$
\begin{aligned}
\kappa= & \left\{\lambda_{\mathrm{H}^{+}}^{o}\left[\mathrm{H}^{+}\right]+\lambda_{\mathrm{OH}^{-}}^{o}\left[\mathrm{OH}^{-}\right]+\sum_{j=0}^{n}\left(|j-a| \lambda_{j}^{o}\left[H_{j} L\right]\right)\right\} \\
& +\left\{\left|z_{\mathrm{Q}_{T}}\right| \lambda_{\mathrm{Q}_{T}}^{o}\left[\mathrm{Q}_{T}\right]+\sum_{j=0}^{n}\left(|j-a| \lambda_{\mathrm{Q}_{j}}^{o}\left[\mathrm{Q}_{j}\right]\right)\right\} \\
= & \left\{\lambda_{\mathrm{H}^{+}}^{o}\left[\mathrm{H}^{+}\right]+\lambda_{\mathrm{OH}^{-}}^{o} \frac{K_{w}}{\left[\mathrm{H}^{+}\right]}+\frac{V_{o} C_{o}}{V_{o}+V} \sum_{j=0}^{n}\left(|j-a| \lambda_{H_{j} L}^{o} f_{j}\right)\right\}
\end{aligned}
$$

$$
\begin{aligned}
& +\left\{\left|z_{\mathrm{Q}_{T}}\right| \lambda_{\mathrm{Q}_{T}}^{o} \frac{V C}{V_{o}+V}+\sum_{j=0}^{n}\left(|j-a| \lambda_{\mathrm{Q}_{j}}^{o} \frac{V_{o} C_{o j}}{V_{o}+V}\right)\right\} \\
& \approx\left\{\lambda_{\mathrm{H}^{+}}\left[\mathrm{H}^{+}\right]+\lambda_{\mathrm{OH}^{-}} \frac{K_{w}}{\left[\mathrm{H}^{+}\right]}+\frac{V_{o} C_{o}}{V_{o}+V} \sum_{i=0}^{n}\left(|j-a| \lambda_{H_{j} L} f_{j}\right)\right\} \\
& +\left\{\left|z_{\mathrm{Q}_{T}}\right| \lambda_{\mathrm{Q}_{T}} \frac{V C}{V_{o}+V}+\sum_{j=0}^{n}\left(|j-a| \lambda_{\mathrm{Q}_{j}} \frac{V_{o} C_{o j}}{V_{o}+V}\right)\right\} .
\end{aligned}
$$

It must be pointed out that the second term in (7) involves the autoprotolysis equilibrium. The third term in this equation rests its greater dependence on the $\mathrm{pH}$ following (4), which involves the global formation equilibria of the species from the protons polydonor system. The fourth term, which comes from the spectator counterion that accompanies the acid or basic particle of the solvent as titrant, has a direct dependence with $V$ through (5) or (6), depending on the case. The last term is the one that comes from the counterions of the species of the protons polydonor system and almost does not depend on $\mathrm{pH}$. The dependence of the third, fourth, and fifth terms in (7) with the $\mathrm{pH}$, through the $V$ that appears in the denominator, is very small and practically null if there were little dilution during the course of titration.

Further, (7) provokes the use of a spread sheet or software to estimate titration plots $\mathrm{pH}=f(V)$ using (5) and (6): with it, it becomes possible to estimate also (exactly) the electric conductivities of the system at every $\mathrm{pH}$ and, hence, at every added volume $V$, provided the equivalent conductivities are given of all ions comprised in the titration. This leads then to the determination of the conductometric titration plots $\kappa=$ $f(V)$ using (7).

The robust model also leads to obtaining many more points with very small $\mathrm{pH}$ increments; therefore, small $V$ increments allow estimating the derivatives through the ratio of the said increments: $d \mathrm{pH} / d V \approx \Delta \mathrm{pH} / \Delta V$ and $d \kappa / d V \approx$ $\Delta \kappa / \Delta V$.

2.1.2. Acid-Base Titrations of Mixtures of Species in Solution That Come from Different Protons Polydonor Systems. When there is a mixture of species that comes from various particle polydonor systems, even when the problem of determining the titration plots of these systems can appear to be much more difficult, it turns out to be of practically equal complexity; the same methodology is followed as described in the previous section.

This is even when the polynomial to be dealt with in $\left[\mathrm{H}^{+}\right]$can be of higher order every time, considering more particle polydonor systems (or more components with acidbase properties); the electroneutrality equation and the other independent equations of the system involve a $V$ only in linear terms, which allows factorizing this variable, and solve it in simpler manner.

The result is that the terms under the summation sign over the index $j$ in (5), (6), and (7) transform into a double sum: the first over the species of a polydonor system and 
the second over the components present in the different polydonor systems [17].

\subsection{Experimental}

2.2.1. Reagents. All reagents used were of analytical grade to prepare the dissolutions described in this paper in deionized water type I $(18.2 \mathrm{M} \Omega \mathrm{cm})$, from a Milli-Q equipment, Millipore. The $\mathrm{NaOH}$ (99\%, Baker) used was free from carbonate and was titrated with potassium hydrogen phthalate (Merck), following the procedures described by Harris [18].

Concentrated $\mathrm{H}_{2} \mathrm{SO}_{4}$ (98\%, Baker) was used to prepare a nominal solution $0.025 \mathrm{~mol} \cdot \mathrm{L}^{-1}$ of sulfuric acid, which was titrated with $\mathrm{NaOH}$, for the first part of this work.

$\mathrm{CH}_{3} \mathrm{COOH}$ (glacial, Baker) and $\mathrm{H}_{3} \mathrm{BO}_{3}$ (99\%, Baker) were used to prepare the nominal solutions $0.05 \mathrm{~mol} \cdot \mathrm{L}^{-1}$ acetic acid and $0.10 \mathrm{~mol} \cdot \mathrm{L}^{-1}$ boric acid, and the mixture of $20 \mathrm{~mL}$ of each one was titrated with $\mathrm{NaOH}$, in the second part of the present paper.

Finally, $\mathrm{CH}_{3} \mathrm{COOH}$ (glacial, Baker), $\mathrm{H}_{3} \mathrm{PO}_{4}$ (85\%, Baker), and $\mathrm{H}_{3} \mathrm{BO}_{3}$ (99\%, Baker) were employed to prepare the equimolar nominal solutions $0.015 \mathrm{~mol} \cdot \mathrm{L}^{-1}$ acetic acid, phosphoric acid, and boric acid. The mixture of $30 \mathrm{~mL}$ or each one, known as Britton-Robinson solution, was titrated with $\mathrm{NaOH}$, in the third part of this contribution.

2.2.2. Equipment and Materials Used for Preparation of Solutions and Titrations. Solid reagents were accurately weighed on an analytical balance OHAUS (Discovery, DV215CD), with a readability of $0.01 \mathrm{mg}$.

Liquid reagents were dispensed with plastic pipettes brand (Transferpette, adjustable) $704174(10-100 \mu \mathrm{L}), 704180$ $(100-1000 \mu \mathrm{L})$, or $704182(0.5-5 \mathrm{~mL})$, with accuracy better than or equal to $0.6 \%$ or glass volumetric pipettes (Pyrex, Class A) of 1,10 , or $20 \mathrm{~mL}$ of capacity, with accuracy better than or equal to $0.6 \%$, were used in order to dispense the adequate amounts of the diverse liquid reagents to prepare solutions.

Glass volumetric flasks (Pyrex, Class A) of 100 or $250 \mathrm{~mL}$, with tolerance better than or equal to $0.8 \%$, were used to fill the volume to the mark.

Glass burettes (Kimax, Class B) of 10, 25, or $50 \mathrm{~mL}$ of capacity, with tolerance better than or equal to $0.4 \%$, were used to dispense the titrant volumes.

2.2.3. Conductometric Titrations Using Initial Large Dissolution Volumes. A laboratory instrument (PC45, Conductronic, Mexico) was used, which was equipped with a temperature sensor and a cylindrical conductivity cell of immersion (C1, $8 \mathrm{~mL}$ capacity: $1 \mathrm{~cm}$ internal diameter, $10 \mathrm{~cm}$ height). The cell has two platinized nickel electrodes, electric contact type mini DIN, and a cell constant $H=1 \mathrm{~cm}^{-1}$ (readability of $1 \mu \mathrm{S}$ ). The minimum volume of solution required to cover all the inner cavity of the conductivity cell was $350 \mathrm{~mL}$, contained in a $600 \mathrm{~mL}$ beaker. The equipment was calibrated with an aqueous standard $\mathrm{KCl} 0.01 \mathrm{M}$ solution (Hach) with $1.413 \mathrm{mS} \mathrm{cm}^{-1}$ conductivity at $25^{\circ} \mathrm{C}$. The solution was vigorously stirred for 2 minutes after every titrant addition with a magnetic stirrer; then the stirring was suspended in order to take a stable conductivity recording.

2.2.4. Conductometric Titrations Using Initial Small Dissolution Volumes. A laboratory instrument (CDM230, Radiometer, Denmark) was used, equipped with a conductivity cell CDC641T with temperature sensor and a cable A94P002. The cell has platinized nickel electrodes and a cell constant $H=1 \mathrm{~cm}^{-1}$ (readability better than $1 \mu \mathrm{S}$ ). The minimum volume of solution required to cover all the inner cavity of the conductivity cell was $30 \mathrm{~mL}$, contained in a $100 \mathrm{~mL}$ beaker. The equipment was calibrated and used as described in the previous paragraph.

2.2.5. pH-Metric Titration. A Conductronic PC45 (Mexico) laboratory instrument was used, which was equipped with a temperature sensor and a PC100 combined electrode with a BNC electric contact $(\Delta \mathrm{pH}= \pm 0.01)$. The equipment was calibrated with a $\mathrm{pH}=7.00$ buffer solution (Radiometer, $\mathrm{pH}$ $7.00)$, taking $\mathrm{pH}$ and potential difference ( $\Delta E$ in millivolts) recordings after addition of every volume of the titrant in turn; in order to correct the $\mathrm{pH}$ through the cell efficiency the following equation was used, as described by Islas-Martínez et al. [19]:

$$
\mathrm{pH}_{\text {corr }}=\mathrm{pH}+e f\left|\frac{\mathrm{pH}-\mathrm{pH}_{\mathrm{cal}}}{\mathrm{pH}_{\mathrm{cal}}}\right| \text {. }
$$

ef is an empirical parameter that relates the inverse of the cell efficiency, $\mathrm{pH}_{\text {cal }}$ is the calibration $\mathrm{pH}$ at a point (in this case $\mathrm{pH}_{\text {cal }}=7.00$ ), and $\mathrm{pH}_{\text {corr }}$ is the corrected $\mathrm{pH}$ from the proportional systematic error to obtain the one that should have been determined for a $100 \%$ cell efficiency and $25^{\circ} \mathrm{C}$ temperature. The parameter $e f$ is varied up to where the slope of the $\Delta E=f\left(\mathrm{pH}_{\text {corr }}\right)$ plot becomes equal to $-59.16 \mathrm{mV}$. In this work, whenever the experimental $\mathrm{pH}=f(V)$ titration graphs are presented, it is actually the $\mathrm{pH}_{\text {corr }}$ that is being plotted, as explained in this section.

\section{Results and Discussion}

In order to corroborate the equations above, the following are adequate model examples to predict the conductometric acid-base titration plots exactly.

3.1. Conductometric Titrations of Aqueous Sulfuric Acid Solutions, at Different Concentrations, with $\mathrm{NaOH}$. This first system constitutes a relatively simple case since sulfuric acid is a diprotic acid where the first dissociation is strong and the ampholyte (formal) of the system has a relatively low $\mathrm{p} K_{a}$. The study was carried out at two different solute concentrations, in agreement with two procedures. The theory for this system corresponds to the first part of Section 2.1, because it corresponds to a species mixture of the same polydonor system. 
TABLE 1: Comparison of the $\mathrm{p} K_{a}$ and the limiting equivalent conductivities values from different sources, at $T=25^{\circ} \mathrm{C}$ and zero ionic strength, with the $\mathrm{p} K_{a}$ and the equivalent conductivities values used to construct the plots in Figures 1-7 with a robust model to perform the estimation.

\begin{tabular}{|c|c|c|c|c|c|}
\hline Species & $\begin{array}{l}\mathrm{p} K_{a} \text { at zero ionic } \\
\text { strength }^{\mathrm{b}}\end{array}$ & $\begin{array}{c}\mathrm{p} K_{a} \text { used for } \\
\text { the fitting } \\
\text { (Figure 1) }\end{array}$ & $\begin{array}{c}\mathrm{p} K_{a} \text { used for } \\
\text { the fitting (Figures } \\
2 \text { and } 3 \text { ) }\end{array}$ & $\begin{array}{l}\mathrm{p} K_{a} \text { used for the } \\
\text { fitting (Figures } 4 \\
\text { and 5) }\end{array}$ & $\begin{array}{c}\mathrm{p} K_{a} \text { used for the } \\
\text { fitting (Figures } 6 \\
\text { and 7) }\end{array}$ \\
\hline $\mathrm{H}_{2} \mathrm{O}^{\mathrm{a}}$ & 14.00 & 13.8 & 13.8 & 13.7 & 13.8 \\
\hline $\mathrm{HSO}_{4}^{-}$ & 1.98 & 1.75 & 1.6 & & \\
\hline $\mathrm{CH}_{3} \mathrm{COOH}$ & 4.757 & & & 4.6 & 4.7 \\
\hline $\mathrm{H}_{3} \mathrm{BO}_{3}$ & 9.24 & & & 9.1 & 9.2 \\
\hline $\mathrm{H}_{3} \mathrm{PO}_{4}$ & 2.149 & & & & 2.1 \\
\hline $\mathrm{H}_{2} \mathrm{PO}_{4}^{-}$ & 7.207 & & & & 7.1 \\
\hline $\mathrm{HPO}_{4}{ }^{2-}$ & 12.346 & & & & 12.3 \\
\hline Ion & $\lambda_{\text {ion }}{ }^{\circ} / \mathrm{mS} \cdot \mathrm{eq}^{-1} \cdot \mathrm{cm}^{2}$ & $\begin{array}{c}\lambda_{\text {ion }} / \mathrm{mS} \cdot \mathrm{eq}^{-1} \cdot \mathrm{cm}^{2} \\
\text { Figure } 1\end{array}$ & $\begin{array}{c}\lambda_{\text {ion }} / \mathrm{mS} \cdot \mathrm{eq}^{-1} \cdot \mathrm{cm}^{2} \\
\text { Figures } 2 \text { and } 3\end{array}$ & $\begin{array}{c}\lambda_{\text {ion }} / \mathrm{mS} \cdot \mathrm{eq}^{-1} \cdot \mathrm{cm}^{2} \\
\text { Figures } 4 \text { and } 5\end{array}$ & $\begin{array}{l}\lambda_{\text {ion }} / \mathrm{mS} \mathrm{eq}^{-1} \cdot \mathrm{cm}^{2} \\
\text { Figures } 6 \text { and } 7\end{array}$ \\
\hline $\mathrm{H}^{+}$ & $\begin{array}{l}349.6^{\mathrm{c}} \\
350.0^{\mathrm{d}} \\
350.1^{\mathrm{e}} \\
\end{array}$ & 350.1 & 350.1 & 350.1 & 350.1 \\
\hline $\mathrm{OH}^{-}$ & $\begin{array}{l}198.0^{\mathrm{c}} \\
199.2^{\mathrm{e}}\end{array}$ & 195.0 & 190.0 & 190.0 & 199.0 \\
\hline $\mathrm{Na}^{+}$ & $50.11^{\mathrm{c}, \mathrm{e}}$ & 50.11 & 50.0 & 49.0 & 50.0 \\
\hline $\mathrm{HSO}_{4}{ }^{-}$ & $50.0^{\mathrm{e}}$ & 50.0 & 49.0 & & \\
\hline $\mathrm{SO}_{4}{ }^{2-}$ & $\begin{array}{l}79.8^{\mathrm{c}} \\
80.0^{\mathrm{e}}\end{array}$ & 86.0 & 60.0 & & \\
\hline $\mathrm{CH}_{3} \mathrm{COO}^{-}$ & $\begin{array}{l}40.9^{\mathrm{c}} \\
41.0^{\mathrm{e}}\end{array}$ & & & 41.0 & 38.0 \\
\hline $\mathrm{H}_{2} \mathrm{BO}_{3}^{-}$ & - & & & 22.0 & 20.0 \\
\hline $\mathrm{H}_{2} \mathrm{PO}_{4}^{-}$ & $36.9^{\mathrm{e}}$ & & & & 10.0 \\
\hline $\mathrm{HPO}_{4}{ }^{2-}$ & $57.0^{\mathrm{e}}$ & & & & 29.0 \\
\hline $\mathrm{PO}_{4}^{3-}$ & $69.0^{\mathrm{e}}$ & & & & 45.0 \\
\hline
\end{tabular}

${ }^{\mathrm{a}}$ The value of $\mathrm{p} K_{w}$ is reported in this line.

${ }^{\mathrm{b}}$ Puigdomenech [20].

${ }^{\mathrm{c}}$ Bard and Faulkner [2].

${ }^{\mathrm{d}}$ Pingarrón [3].

${ }^{\mathrm{e}}$ Dean [4].

In order to explain better the treatment described in Section 2.1, (9) presents the algebra of the fractions of the sulfate species as a function of $\mathrm{pH}$ :

$$
\begin{gathered}
f_{\mathrm{SO}_{4}{ }^{2-}}=\frac{\left[\mathrm{SO}_{4}{ }^{2-}\right]}{[\text { Sulfate }]_{\text {total }}}=\frac{1}{1+10^{\left(\mathrm{pK}_{\left.\mathrm{HSO}_{4}-\mathrm{pH}\right)}\right.}} \\
f_{\mathrm{HSO}_{4}{ }^{-}}=\frac{\left[\mathrm{HSO}_{4}{ }^{-}\right]}{[\text {Sulfate }]_{\text {total }}}=f_{\mathrm{SO}_{4}{ }^{2-} 10^{\left(\mathrm{pK}_{\mathrm{HSO}_{4}}-\mathrm{pH}\right)}}
\end{gathered}
$$

$\mathrm{p} K_{\mathrm{HSO}_{4}}$ being the $\mathrm{p} K_{a}$ of the hydrogen sulfate ion.

Equation (10) expresses the volume of strong base added in these titrations as a function of $\mathrm{pH}$ :

$$
V_{b}=\frac{-V_{o} C_{o}\left[2 f_{\mathrm{SO}_{4}{ }^{2-}}+f_{\mathrm{HSO}_{4}^{-}}\right]-V_{o}\left(\left[\mathrm{H}^{+}\right]-K_{w} /\left[\mathrm{H}^{+}\right]\right)}{C_{b}+\left[\mathrm{H}^{+}\right]-K_{w} /\left[\mathrm{H}^{+}\right]} .
$$

Finally (11) expresses the conductivity as a function of $\mathrm{pH}$ :

$$
\begin{aligned}
\kappa= & \lambda_{\mathrm{H}^{+}}\left[\mathrm{H}^{+}\right]+\lambda_{\mathrm{OH}^{-}} \frac{K_{w}}{\left[\mathrm{H}^{+}\right]} \\
& +\frac{V_{o} C_{o}}{V_{o}+V_{b}}\left(\lambda_{\mathrm{HSO}_{4}} f_{\mathrm{HSO}_{4}^{-}}+2 \lambda_{\mathrm{SO}_{4}{ }^{2-}} f_{\mathrm{SO}_{4}{ }^{2-}}\right) \\
& +\lambda_{\mathrm{Na}^{+}} \frac{V_{b} C_{b}}{V_{o}+V_{b}} .
\end{aligned}
$$

3.1.1. Procedure 1. $20.00 \mathrm{~mL}$ of the $0.024 \mathrm{~mol} \mathrm{~L}^{-1}$ sulfuric acid aqueous solution was used to which $430.0 \mathrm{~mL}$ of deionized water was added (giving as a result $V_{o}=450.0 \mathrm{~mL}$ and $C_{o}=$ $0.00107 \mathrm{~mol} \mathrm{~L}^{-1}$ ). This solution was titrated with a sodium hydroxide aqueous solution at a $C_{b}=0.2743 \mathrm{~mol} \mathrm{~L}^{-1}$ concentration. With these titration conditions and the parameters shown in Table 1 introduced in (9) and (10), it is possible to construct the pH-metric titration plot shown in Figure 1(a) (solid line). 


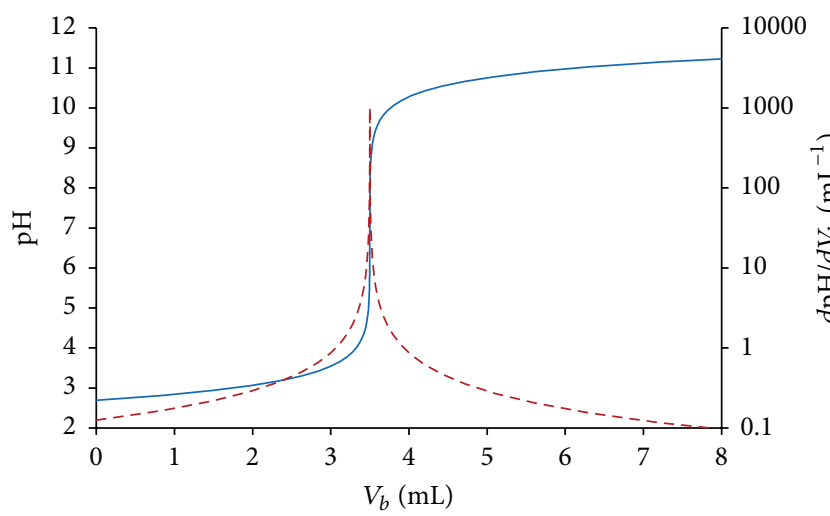

(a)

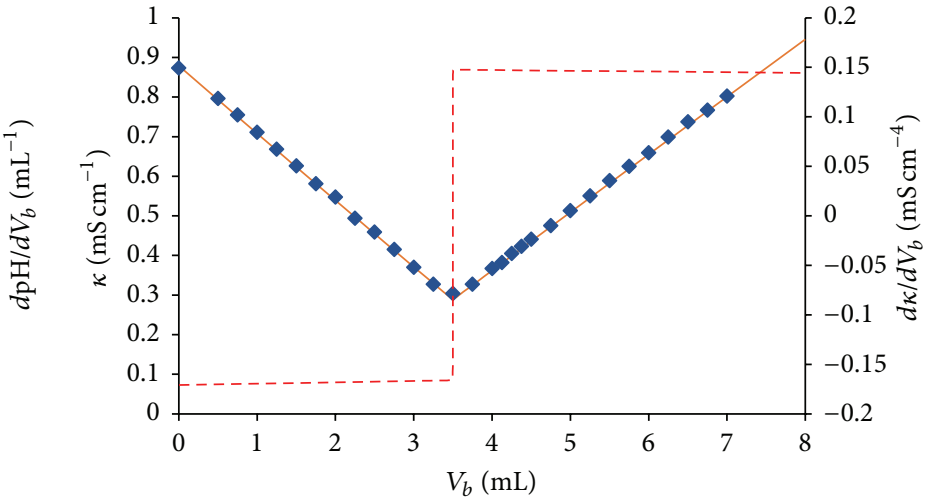

(b)

FIGURE 1: Plots obtained during titration of $20.00 \mathrm{~mL} \mathrm{H}_{2} \mathrm{SO}_{4} 0.024 \mathrm{M}+430.0 \mathrm{~mL}$ deionized water with $\mathrm{NaOH} 0.2743 \mathrm{M}$, at $25^{\circ} \mathrm{C}$. (a) $\mathrm{pH}$-metric plots: the solid line represents the plot $\mathrm{pH}=f\left(V_{b}\right)$ obtained with (10) while the segmented line represents the plot of $d \mathrm{pH} / d V_{b}=f^{\prime}\left(V_{b}\right) \approx$ $\Delta \mathrm{pH} / \Delta V_{b}$. (b) Conductometric plot $\kappa=g\left(V_{b}\right)$. The markers represent the experimental points obtained and the solid line represents the estimated plot with (11); the segmented line represents the plot $d \kappa / d V_{b}=g^{\prime}\left(V_{b}\right) \approx \Delta \kappa / \Delta V_{b}$, obtained from the fitted model.

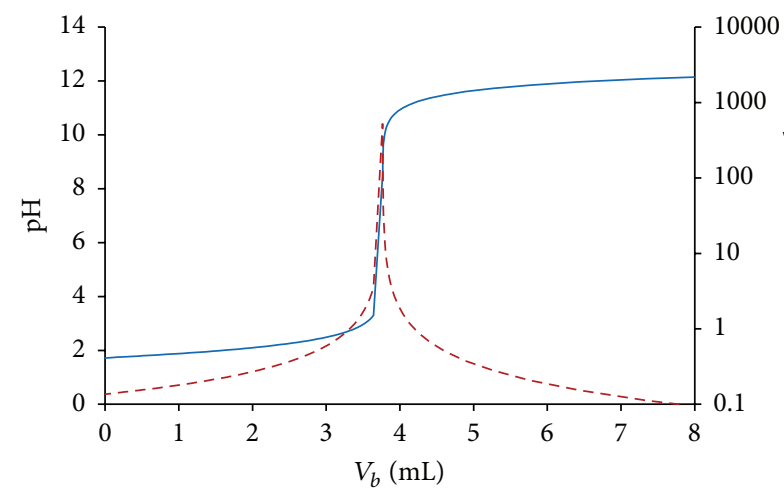

(a)

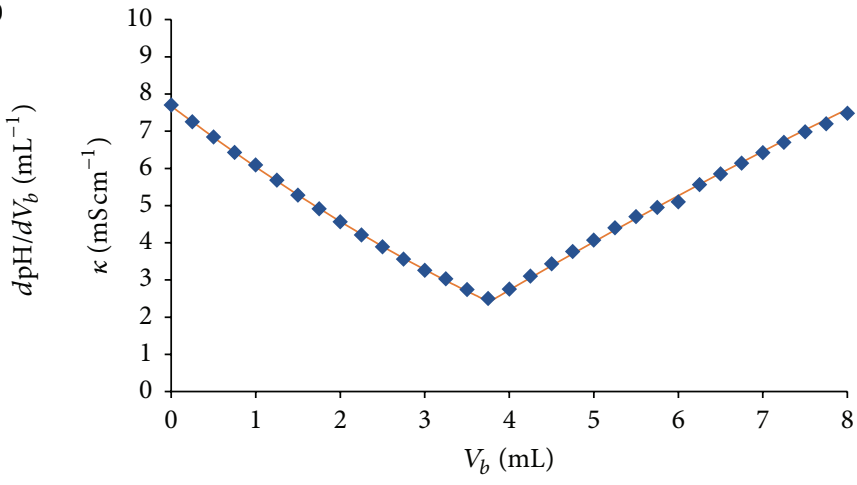

(b)

Figure 2: Plots obtained during titration of $20.00 \mathrm{~mL} \mathrm{H}_{2} \mathrm{SO}_{4} 0.024 \mathrm{M}+20.0 \mathrm{~mL}$ deionized water with $\mathrm{NaOH} 0.2550 \mathrm{M}$, at $25^{\circ} \mathrm{C}$. (a) pH-metric plots: the solid line represents the plot $\mathrm{pH}=f\left(V_{b}\right)$ obtained with (10) while the segmented line represents the plot of $d \mathrm{pH} / d V_{b}=f^{\prime}\left(V_{b}\right) \approx$ $\Delta \mathrm{pH} / \Delta V_{b}$. (b) Conductometric plot $\kappa=g\left(V_{b}\right)$. The markers represent the experimental points obtained and the solid line represents the estimated plot with (11).

Also, Figure 1(a) shows the plot of the first $\mathrm{pH}$ derivative as a function of volume in a log scale (broken line, obtained approximately). The conductometric plot, estimated through (9), (10), and (11) (solid line), and the experimental one (markers) are shown in Figure 1(b), which also shows the plot of the first derivative of the conductivity as a function of volume (broken line). The plots shown in Figure 1 are just like those that would be obtained for the titration of a strong acid with a strong base, just as if the sulfuric acid was a strong acid in both dissociations. It is relevant to underline that the estimated conductometric plot (solid line in Figure 1(b)) is practically equal to the trace of the experimental (markers) and seems to comprise two straight lines, the intersection of which would indicate the volume of the reaction equivalence point:

$$
\mathrm{R}: \mathrm{H}^{+}+\mathrm{OH}^{-} \leftrightarrows \mathrm{H}_{2} \mathrm{O}, \quad \text { with } K_{\mathrm{R}}=10^{13.8}
$$

$\left(K_{\mathrm{R}}=10^{14.0}\right.$ at zero ionic strength and $\left.T=25^{\circ} \mathrm{C}\right)$ which is practically an acid-base reaction with the largest conversion in aqueous solutions, because it has the greatest reaction constant.

The fitting of the model into the experimental results, presented in Figure 2(b), used the values of the equilibrium constants and of the equivalent conductivity for the ions appearing in Table 1, where it can be clearly noted that the values used for the fitting are indeed similar to those reported in the literature. Also, in Figure 2(b) the plot of the conductivity first derivative with respect to volume appears to be formed by two straight lines crossing at the equivalence point, just so where the derivative changes abruptly, though in this case, passing through zero.

3.1.2. Procedure 2. $20.00 \mathrm{~mL}$ of the $0.024 \mathrm{~mol} \mathrm{~L}^{-1}$ sulfuric acid aqueous solution was mixed with $20.00 \mathrm{~mL}$ deionized water (thus giving a $V_{o}=40.0 \mathrm{~mL}$ and a $C_{o}=0.012 \mathrm{~mol} \mathrm{~L}^{-1}$ ). 
This solution was titrated with an aqueous sodium hydroxide solution at a concentration of $C_{b}=0.2550 \mathrm{~mol} \mathrm{~L}^{-1}$. With these titration conditions the titration $\mathrm{pH}$-metric plot was estimated: this is shown in Figure 2(a) (solid line) and its derivative is also included (broken line), whereas the conductometric plots, estimated (solid line) and experimental (markers), are shown in Figure 2(b).

The $\mathrm{pH}$-metric plot and its first derivative (Figure 2(a)) are like those obtained in procedure 1 and could be interpreted in the same form, as if the sulfuric acid displayed two strong dissociations. However, Figure 2(b) is quite different to Figure 2(a), even if the estimated line (solid line) remains practically the same with respect to the experimental (markers), because it does not comprise two straight lines, but two curved sections that intersect at the equivalence point volume. The fitting of the conductometric line was carried out with the $\mathrm{p} K_{a}$ values and equivalent conductivities presented in Table 1 that, as can be noted, are slightly smaller than those of the limiting equivalent conductivities of the species (except for the hydronium ion). This can be because the sulfuric acid concentration in procedure 2 was almost ten times greater than that used in procedure 1.

3.1.3. Comparative Discussion of the Results Obtained with Procedures 1 and 2. The conductometric plot shown in Figure 1(b) comprises practically linear sections because there is very little dilution in the system, in accordance with procedure 1 , since after adding $8.0 \mathrm{~mL}$ to an initial $450.0 \mathrm{~mL}$ volume, the resulting overall volume only augmented $1.7 \%$. Instead, in Figure 2(b) the conductometric plot is formed by two curved sections because when adding $8.0 \mathrm{~mL}$ to an initial $40.00 \mathrm{~mL}$ volume, procedure 2 , the total volume increased $20 \%$.

However, there is another explanation for the difference between the lines presented in Figures 1(b) and 2(b). The initial hydrogen sulfate ion concentration according to procedure 1 , in the initial $450.0 \mathrm{~mL}$ volume, is $1.07 \times 10^{-3} \mathrm{M}$. If the ionic strength parameter is taken into account, $K_{a} / C_{o}$ of the acid [16] in this solution is obtained at a value of 14.81; or else, $\log \left(K_{a} / C_{o}\right)=1.17$, which implies a dissociation only a little smaller of $80 \%$. Hence, in procedure 1 the hydrogen sulfate ion is a medium strength acid sufficiently dissociated, which tends to be strong, although it becomes stronger as the titration proceeds (because of dilution). Instead, in procedure 2 , the initial hydrogen sulfate ion concentration in the starting $40.00 \mathrm{~mL}$ volume is $0.012 \mathrm{M}$, with which the $K_{a} / C_{o}$ parameter gives an approximate value of 2.09 , or $\log \left(K_{a} / C_{o}\right)=0.32$, which implies a dissociation of about $50 \%$. Hence, in procedure 2 the hydrogen sulfate ion is a medium strength acid which is not dissociated, although it also becomes stronger as the titration proceeds (because of dilution).

Therefore, in order to interpret the shape of the conductometric plot from procedure 2 (which would also be strictly valid for procedure 1) another two titration reactions must be considered. First, the following reaction R1 contributes more to the plot:

$$
\mathrm{R} 1: \mathrm{H}^{+}+\mathrm{OH}^{-} \leftrightarrows \mathrm{H}_{2} \mathrm{O}, \quad \text { with } K_{\mathrm{R} 1}=10^{13.80},
$$

which, when approaching, the first equivalence point (EP1, with $V_{\mathrm{EP} 1} \approx 1.9 \mathrm{~mL}$ ) is not quite quantitative for the acid dissociation of the $\mathrm{HSO}_{4}{ }^{-}$ion; this is why there seems to be no changes on the $\mathrm{pH}$-metric plot in Figure 2(a), not even on its first derivative in log scale, but there is a curvature of the conductometric plot that seems readily noticeable on the conductometric plot of Figure 2(b). This is because the $\mathrm{pH}$-metric titration plots are logarithmic with respect to the hydronium ion concentration, whereas the conductometric ones are linear with respect to the ions concentrations.

In the vicinity of the EP1, it can be considered that the second titration reaction $\mathrm{R} 2$ begins:

$$
\begin{aligned}
& \mathrm{R} 2: \mathrm{HSO}_{4}{ }^{-}+\mathrm{OH}^{-} \leftrightarrows \mathrm{SO}_{4}{ }^{2-}+\mathrm{H}_{2} \mathrm{O}, \quad \text { with } \\
& K_{\mathrm{R} 2}=10^{(13.8-1.6)}=10^{12.2}
\end{aligned}
$$

having an appreciable quantitivity. Therefore, the second equivalence point (EP2, with $V_{\mathrm{EP} 2} \approx 3.8 \mathrm{~mL}$ ) is clearly visible on the conductometric (Figure 2(b)) and in the $\mathrm{pH}$-metric plots (Figure 2(a)).

With the aim of additionally proving that the robust model predicts correctly the conductometric titration plots, Figure 3 presents the behavior of the plot corrected by dilution: $\kappa_{\text {corr }}=f\left(V_{b}\right)$.

Figure 3(a) shows that the correction by dilution increases the conductivity values with respect to the experimental ones, because they are those that would have been measured provided there were no dilution effects. Figure 3(b) leads us to appreciate that, as expected, the dilution correction induces the plot to become linearly segmented from the vicinity of EP2 up to the excess titrant added. However, from the beginning up to the vicinity of EP1 the plot is not linear, because the reaction is not sufficiently quantitative, although it may be fitted by linear segments away from the vicinity of EP1. In fact, the derivative of the conductometric plot (broken line in Figure 3(b)) shows that before EP1 the plot seems to be formed by two quadratic functions of the volume, the intersection of which marks the $V_{\mathrm{EP} 1}$.

The robust estimation model leads to a greater exactness and precision when fitting the experimental results, without the need to correct the conductivity because of the dilution effect. The uncertainty of selecting which points should be considered in the linear trend, before and after the EP1, is still significant in this case (that could be considered a titration case of relatively simple interpretation).

\subsection{Conductometric Titration with $\mathrm{NaOH}$ of a Mixture of} Acetic and Boric Acids in Aqueous Solution. The next case in complexity corresponds to a mixture of monoprotic acids that are titrated with sodium hydroxide. Even though they are monodonor, they form a mixture of species of different systems, like it is commented on the corresponding theory in the second part of Section 2.1. 




(a)

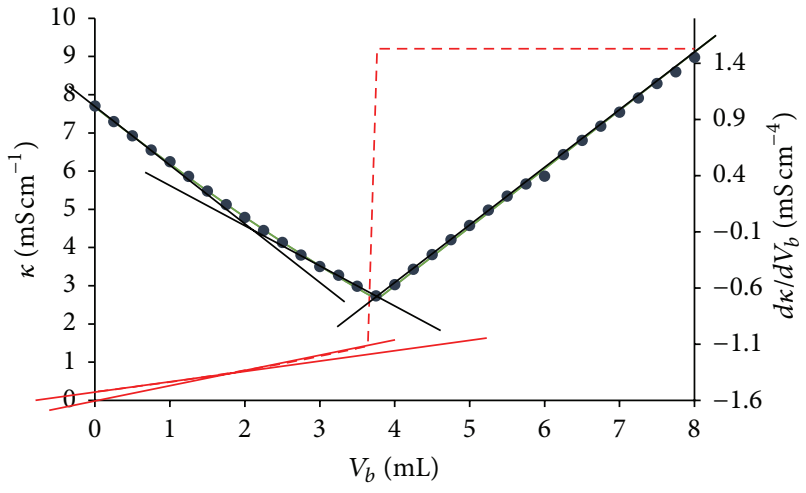

(b)

FIgURE 3: Plots of $\kappa$ and $\kappa_{\text {corr }}$ as a function of $V_{b}$ for the titration system stated in Figure 2. (a) The conductivity plots of the system and corrected conductivity are different because of the large dilution during titration. (b) Experimental plots $\kappa_{\text {corr }}=h\left(V_{b}\right)$ (markers) and estimated with (11) and (3) (solid line), and its first derivative, $d \kappa_{\text {corr }} / d V_{b}=h^{\prime}\left(V_{b}\right) \approx \Delta \kappa_{\text {corr }} / \Delta V_{b}$ (segmented line). Auxiliary thin black and red lines are added to emphasize the linear trends in the corresponding curve.

Further, to facilitate the understanding when studying these systems, the following equations correspond to the fractions of the acetates and borates as a function of $\mathrm{pH}$ :

$$
\begin{aligned}
& f_{\mathrm{CH}_{3} \mathrm{COO}^{-}}=\frac{\left[\mathrm{CH}_{3} \mathrm{COO}^{-}\right]}{[\text {Acetate }]_{\text {total }}}=\frac{1}{1+10^{\left(\mathrm{p} K_{\left.\mathrm{CH}_{3} \mathrm{COOH}^{-} \mathrm{pH}\right)}\right.}},
\end{aligned}
$$

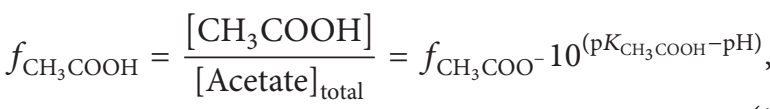

$$
\begin{aligned}
& f_{\mathrm{H}_{2} \mathrm{BO}_{3}{ }^{-}}=\frac{\left[\mathrm{H}_{2} \mathrm{BO}_{3}^{-}\right]}{[\text {Borate }]_{\text {total }}}=\frac{1}{1+10^{\left(\mathrm{pK}_{\left.\mathrm{H}_{3} \mathrm{BO}_{3}-\mathrm{pH}\right)}\right.}},
\end{aligned}
$$

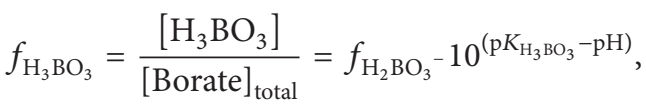

where $\mathrm{p} K_{\mathrm{CH}_{3} \mathrm{COOH}}$ is the $\mathrm{p} K_{a}$ of the acetic acid and $\mathrm{p} K_{\mathrm{H}_{3} \mathrm{BO}_{3}}$ the $\mathrm{p} K_{a}$ of the boric acid.

Equation (17) expresses the volume of the strong base added during titration of mixtures of acetic acid and boric acid as a function of $\mathrm{pH}$ :

$$
\begin{aligned}
& V_{b}=\left(-V_{o} C_{o}\left[f_{\mathrm{CH}_{3} \mathrm{COO}^{-}}\right]-V_{o} C_{1}\left[f_{\mathrm{H}_{2} \mathrm{BO}_{3}^{-}}\right]\right. \\
& \left.-V_{o}\left(\left[\mathrm{H}^{+}\right]-\frac{K_{w}}{\left[\mathrm{H}^{+}\right]}\right)\right)\left(C_{b}+\left[\mathrm{H}^{+}\right]-\frac{K_{w}}{\left[\mathrm{H}^{+}\right]}\right)^{-1},
\end{aligned}
$$

where $C_{o}$ is the initial concentration of acetic acid and $C_{1}$ is the initial concentration of boric acid in the volume $V_{o}$ of the mixture.
Finally, (18) presents the expression of the conductivity in the same titrations as a function of $\mathrm{pH}$ :

$$
\begin{aligned}
\kappa= & \lambda_{\mathrm{H}^{+}}\left[\mathrm{H}^{+}\right]+\lambda_{\mathrm{OH}^{-}} \frac{K_{w}}{\left[\mathrm{H}^{+}\right]}+\frac{V_{o} C_{o}}{V_{o}+V_{b}} \lambda_{\mathrm{CH}_{3} \mathrm{COO}^{-}} f_{\mathrm{CH}_{3} \mathrm{COO}^{-}} \\
& +\frac{V_{o} C_{1}}{V_{o}+V_{b}} \lambda_{\mathrm{H}_{2} \mathrm{BO}_{3}} f_{\mathrm{H}_{2} \mathrm{BO}_{3}{ }^{-}}+\lambda_{\mathrm{Na}^{+}} \frac{V_{b} C_{b}}{V_{o}+V_{b}} .
\end{aligned}
$$

3.2.1. Procedure. $20.0 \mathrm{~mL}\left(V_{o}\right)$ of an aqueous solution having a $C_{o}=0.053 \mathrm{~mol} \mathrm{~L}^{-1}$ concentration in $\mathrm{CH}_{3} \mathrm{COOH}$ and a concentration $C_{1}=0.1025 \mathrm{~mol} \mathrm{~L}^{-1}$ in $\mathrm{H}_{3} \mathrm{BO}_{3}$ was titrated with a $\mathrm{NaOH}$ aqueous solution at a $C_{b}=0.2743 \mathrm{~mol} \mathrm{~L}^{-1}$ concentration.

Figure 4 presents the $\mathrm{pH}$-metric titration plot (estimated with (15), (16), and (17)), as well as its first derivative and the conductometric plot (experimental and estimated) of the titration described in the previous procedure. The data shown in Table 1 were considered in the estimates.

The $\mathrm{pH}=f\left(V_{b}\right)$ plot (solid line), and its first derivative with respect to $V_{b}$ (broken line), shows that it is possible to determine exactly and precisely the two equivalence points existing in the titration (Figure 4(a)).

As the acetic acid $\mathrm{p} K_{a}$ is smaller than that of the boric acid, the first titration reaction (R1) is

$$
\begin{aligned}
& \mathrm{R} 1: \mathrm{CH}_{3} \mathrm{COOH}+\mathrm{OH}^{-} \leftrightarrows \mathrm{CH}_{3} \mathrm{COO}^{-}+\mathrm{H}_{2} \mathrm{O} \quad \text { with } \\
& K_{\mathrm{R} 1}=10^{(14.0-4.6)}=10^{9.4}
\end{aligned}
$$

whereas the second (R2) is

$$
\begin{aligned}
& \mathrm{R} 2: \mathrm{H}_{3} \mathrm{BO}_{3}+\mathrm{OH}^{-} \leftrightarrows \mathrm{H}_{2} \mathrm{BO}_{3}^{-}+\mathrm{H}_{2} \mathrm{O} \text { with } \\
& K_{\mathrm{R} 2}=10^{(14.0-9.1)}=10^{4.9} .
\end{aligned}
$$

The robust model for estimation of the conductometric plot described in the present work allows an excellent fit of the 


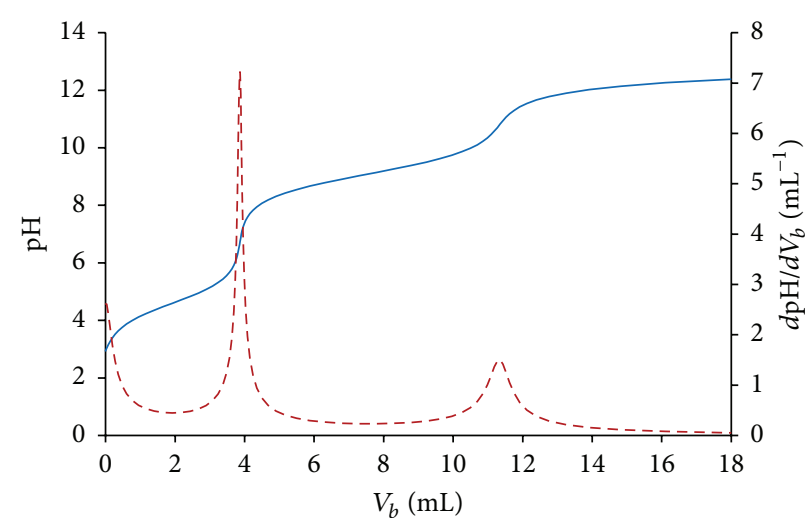

(a)

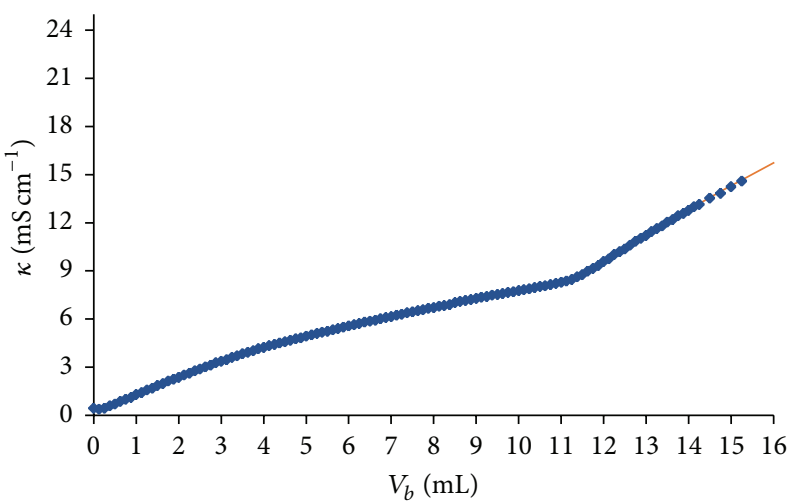

(b)

FIGURE 4: Plots obtained during titration of $20.00 \mathrm{~mL}$ of $\mathrm{CH}_{3} \mathrm{COOH}$ aqueous solution at a $0.053 \mathrm{~mol} \mathrm{~L}^{-1}$ concentration and $\mathrm{H}_{3} \mathrm{BO}_{3}$ at a $0.1025 \mathrm{~mol} \mathrm{~L}^{-1}$ concentration, with $\mathrm{NaOH}$ aqueous solution at $0.2743 \mathrm{~mol} \mathrm{~L}^{-1}$ concentration. (a) Calculated pH-metric plots: the solid line represents the plot $\mathrm{pH}=f\left(V_{b}\right)$ obtained with (17) while the segmented line represents the plot of $d \mathrm{pH} / d V_{b}=f^{\prime}\left(V_{b}\right) \approx \Delta \mathrm{pH} / \Delta V_{b}$. (b) Conductometric plot $\kappa=g\left(V_{b}\right)$. The markers represent the experimental points obtained and the solid line represents the estimated plot with (18).

experimental plot, as can be appreciated in Figure 4(b), even if the plot is clearly nonlinear, because of the large dilution taking place in the system. The values of $\mathrm{p} K_{a}$ and equivalent conductivity were used for the fitting, in accordance with (15), (16), (17), and (18), and are shown in Table 1.

When performing the dilution correction to the conductivity, it can be observed that the $\kappa_{\text {corr }}$ increases at every conductivity measurement, $\kappa$ (Figure $5(\mathrm{a})$ ). Further, straight lines have been added over the $\kappa_{\text {corr }}$; in Figure 5(b), these can be used to perform the quantitative analysis of this type of mixture, in spite of the fact that the first titration reaction is more quantitative, whereas the slope change in the corrected conductometric plot is more difficult to appreciate (because the slopes of the straight lines before and after the EP1 are almost equal). Without the robust estimation model it may become difficult to locate adequately the EP1 and consequently the selection of points before and after the EP1 that follow the linear trend, to determine the volume of the said EP1, exactly and precisely, by means of the intersection of the two straight lines.

However, there is another contribution to the fitting of the estimation robust model that allows also obtaining a good approximation for the derivative of the corrected conductivity as a function of $\mathrm{pH}$ (broken line in Figure 5(b)). In the EP1 region it can be observed that a constant (the slope of the straight line that appears before the EP1) changes abruptly into another constant (that is the slope of the straight line appearing just after the EP1). This representation is clearer than the search for the straight line trends in a typical conductometric plot.

3.3. Potentiometric and Conductometric Titrations of a Britton-Robinson Aqueous Solution (Mixture of Acetic, Boric, and Phosphoric Acids), with $\mathrm{NaOH}$. The last case considered in this work is a more complicated system than the previous. It was decided to carry out a conductometric titration of a similar solution to that of Britton-Robinson, in agreement with the information found in Dean [4], which implies adding the phosphoric acid (a triprotic acid) to a mixture like the one of the previous section.

Aside from the fact that the mixture studied in this section involves species from three different components, the Britton-Robinson solutions are usually used as universal buffer systems in biologic systems and for biochemical and biotechnological studies. Hence, the characterization of these systems turns out to be relevant.

The estimates of the titration plots for Britton-Robinson solutions involve the fractions of the acetates, (15), borates, (16), and phosphates, (21), systems:

$$
\begin{aligned}
& f_{\mathrm{PO}_{4}{ }^{3-}}=\frac{\left[\mathrm{PO}_{4}{ }^{3-}\right]}{[\text { Phosphate }]_{\text {total }}} \\
& =1\left(1+10^{\left(\mathrm{pK}_{\mathrm{HPO}_{4}}-\mathrm{pH}\right)}+10^{\left(\mathrm{pK}_{\mathrm{HPO}_{4}}+\mathrm{pK}_{\mathrm{H}_{2} \mathrm{PO}_{4}}-2 \mathrm{pH}\right)}\right.
\end{aligned}
$$



$$
\begin{aligned}
& f_{\mathrm{HPO}_{4}{ }^{2-}}=\frac{\left[\mathrm{HPO}_{4}{ }^{2-}\right]}{[\text { Phosphate }]_{\text {total }}}=f_{\mathrm{PO}_{4}{ }^{3-}} 10^{\left(\mathrm{pK}_{\mathrm{HPO}_{4}}-\mathrm{pH}\right)} \\
& f_{\mathrm{H}_{2} \mathrm{PO}_{4}{ }^{-}}=\frac{\left[\mathrm{H}_{2} \mathrm{PO}_{4}{ }^{-}\right]}{[\text {Phosphate }]_{\text {total }}}=f_{\mathrm{PO}_{4}{ }^{3-}} 10^{\left(\mathrm{pK}_{\mathrm{HPO}_{4}}+\mathrm{pK}_{\mathrm{H}_{2} \mathrm{PO}_{4}}-2 \mathrm{pH}\right)} \text {, } \\
& f_{\mathrm{H}_{3} \mathrm{PO}_{4}}=\frac{\left[\mathrm{H}_{3} \mathrm{PO}_{4}\right]}{[\text { Phosphate }]_{\text {total }}}
\end{aligned}
$$

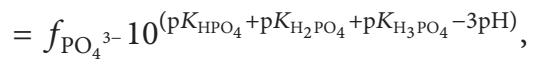

where $\mathrm{p} K_{\mathrm{HPO}_{4}}, \mathrm{p} K_{\mathrm{H}_{2} \mathrm{PO}_{4}}$, and $\mathrm{p} K_{\mathrm{H}_{3} \mathrm{PO}_{4}}$ are the values of $\mathrm{p} K_{a 3}$, $\mathrm{p} K_{a 2}$, and $\mathrm{p} K_{a 1}$, respectively, of the phosphoric acid. 




(a)

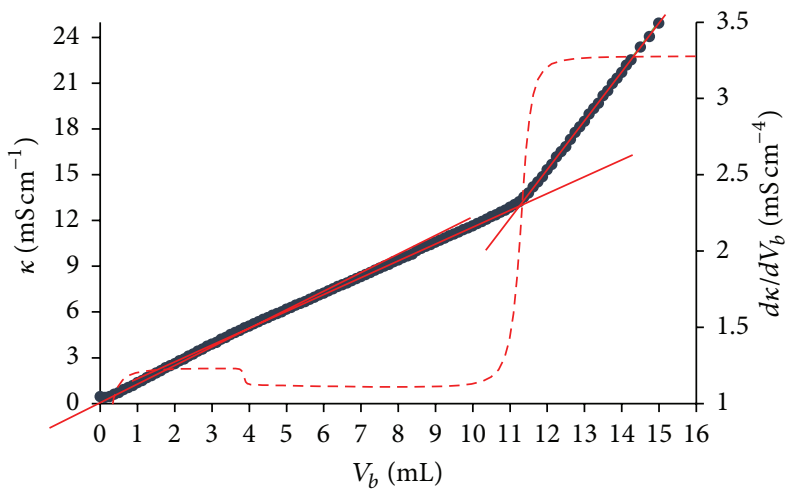

(b)

Figure 5: Plots of $\kappa$ and $\kappa_{\text {corr }}$ as a function of $V_{b}$ for the titration system stated in Figure 4. (a) The conductivity plots of the system and corrected conductivity are different because of the large dilution during titration. (b) Experimental plots $\kappa_{\text {corr }}=h\left(V_{b}\right)$ (markers) and estimated with (18) and (3) (solid line), and its first derivative, $d \kappa_{\text {corr }} / d V_{b}=h^{\prime}\left(V_{b}\right) \approx \Delta \kappa_{\text {corr }} / \Delta V_{b}$ (segmented line).

Equation (22) gives the volume of the strong base added during titrations of Britton-Robinson solutions, as a function of $\mathrm{pH}$ :

$$
\begin{aligned}
V_{b}=( & -V_{o} C_{o}\left[f_{\mathrm{CH}_{3} \mathrm{COO}^{-}}\right]-V_{o} C_{1}\left[f_{\mathrm{H}_{2} \mathrm{BO}_{3}{ }^{-}}\right] \\
& -V_{o} C_{2}\left[3 f_{\mathrm{PO}_{4}{ }^{3-}}+2 f_{\mathrm{HPO}_{4}{ }^{2-}}+f_{\left.\mathrm{H}_{2} \mathrm{PO}_{4}{ }^{-}\right]}\right. \\
& \left.-V_{o}\left(\left[\mathrm{H}^{+}\right]-\frac{K_{w}}{\left[\mathrm{H}^{+}\right]}\right)\right)\left(C_{b}+\left[\mathrm{H}^{+}\right]-\frac{K_{w}}{\left[\mathrm{H}^{+}\right]}\right)^{-1},
\end{aligned}
$$

where $C_{o}$ is the acetic acid initial concentration, $C_{1}$ is the boric acid initial concentration, and $C_{2}$ is the phosphoric acid initial concentration, in the volume $V_{o}$ of the mixture.

Finally (23) gives the expression of the conductivity as a function of $\mathrm{pH}$ for the same titrations:

$$
\begin{aligned}
\kappa= & \lambda_{\mathrm{H}^{+}}\left[\mathrm{H}^{+}\right]+\lambda_{\mathrm{OH}^{-}} \frac{K_{w}}{\left[\mathrm{H}^{+}\right]}+\frac{V_{o} C_{o}}{V_{o}+V_{b}} \lambda_{\mathrm{CH}_{3} \mathrm{COO}^{-}} f_{\mathrm{CH}_{3} \mathrm{COO}^{-}} \\
+ & \frac{V_{o} C_{1}}{V_{o}+V_{b}} \lambda_{\mathrm{H}_{2} \mathrm{BO}_{3}{ }^{-}} f_{\mathrm{H}_{2} \mathrm{BO}_{3}{ }^{-}}+\frac{V_{o} C_{2}}{V_{o}+V_{b}} \\
& \cdot\left(\lambda_{\mathrm{H}_{2} \mathrm{PO}_{4}{ }^{-}} f_{\mathrm{H}_{2} \mathrm{PO}_{4}{ }^{-}}+2 \lambda_{\mathrm{HPO}_{4}{ }^{2-}} f_{\mathrm{HPO}_{4}{ }^{2-}}\right. \\
& \left.+3 \lambda_{\mathrm{PO}_{4}{ }^{3-}} f_{\mathrm{PO}_{4}{ }^{3-}}\right)+\lambda_{\mathrm{Na}^{+}} \frac{V_{b} C_{b}}{V_{o}+V_{b}} .
\end{aligned}
$$

3.3.1. Procedure. An equimolar Britton-Robinson mixture of the acetic, boric, and phosphoric acids was prepared, adding $30 \mathrm{~mL}$ each at $0.015 \mathrm{~mol} \mathrm{~L}^{-1}$ nominal concentrations, and then $260.0 \mathrm{~mL}$ water was added, thus obtaining a nominal concentration of each acid in the mix of $C_{o}=C_{1}=C_{2}=$ $0.001286 \mathrm{~mol} \mathrm{~L}^{-1}$. The volume $V_{o}=350.0 \mathrm{~mL}$ of the initial mix thus prepared was titrated with titrated $\mathrm{NaOH}$ solution (Baker) at a $C_{b}=0.050 \mathrm{M}$ concentration.
3.3.2. Potentiometric Titration. As the reactants used to prepare the solutions of the acids were not primary standards, their quantitative analysis was done from the potentiometric titration. Fitting the plot was done with the robust model, following (22) and with the $K_{a}$ values shown in Table 1; the said fitting is shown in Figure 6(a), as well as its first derivative, obtained in a more approximate manner with the data of the model (which smooths notably the plot and facilitates the detection of the maxima with greater exactness and precision if it were done with the experimental data).

The titration plot presented in Figure 6(a) allows establishing that there are four equivalence points corresponding to the same number of reactions sufficiently quantitative. The analysis of the physicochemical information found in the literature allows concluding that these four titration reactions follow the growing order of the $\mathrm{p} K_{a}$ values, so that

$\mathrm{R} 1: \mathrm{H}_{3} \mathrm{PO}_{4}+\mathrm{OH}^{-} \leftrightarrows \mathrm{H}_{2} \mathrm{PO}_{4}^{-}+\mathrm{H}_{2} \mathrm{O}$ with

$K_{\mathrm{R} 1}=10^{(14.0-2.1)}=10^{11.9}$

$\mathrm{R} 2: \mathrm{CH}_{3} \mathrm{COOH}+\mathrm{OH}^{-} \leftrightarrows \mathrm{CH}_{3} \mathrm{COO}^{-}+\mathrm{H}_{2} \mathrm{O}$ with

$K_{\mathrm{R} 2}=10^{(14.0-4.7)}=10^{9.3}$

R3: $\mathrm{H}_{2} \mathrm{PO}_{4}{ }^{-}+\mathrm{OH}^{-} \leftrightarrows \mathrm{HPO}_{4}{ }^{2-}+\mathrm{H}_{2} \mathrm{O}$ with

$K_{\mathrm{R} 1}=10^{(14.0-7.1)}=10^{6.9}$

R4: $\mathrm{H}_{3} \mathrm{BO}_{3}+\mathrm{OH}^{-} \leftrightarrows \mathrm{H}_{2} \mathrm{BO}_{3}{ }^{-}+\mathrm{H}_{2} \mathrm{O}$ with

$K_{\mathrm{R} 4}=10^{(14.0-9.2)}=10^{4.8}$.

Even when there is a fifth titration reaction in this system, there is not sufficient quantitivity to be appreciated. Such reaction is

$$
\begin{aligned}
& \mathrm{R} 5: \mathrm{HPO}_{4}{ }^{2-}+\mathrm{OH}^{-} \leftrightarrows \mathrm{PO}_{4}{ }^{3-}+\mathrm{H}_{2} \mathrm{O} \text { with } \\
& K_{\mathrm{R} 1}=10^{(14.0-12.3)}=10^{1.7} .
\end{aligned}
$$




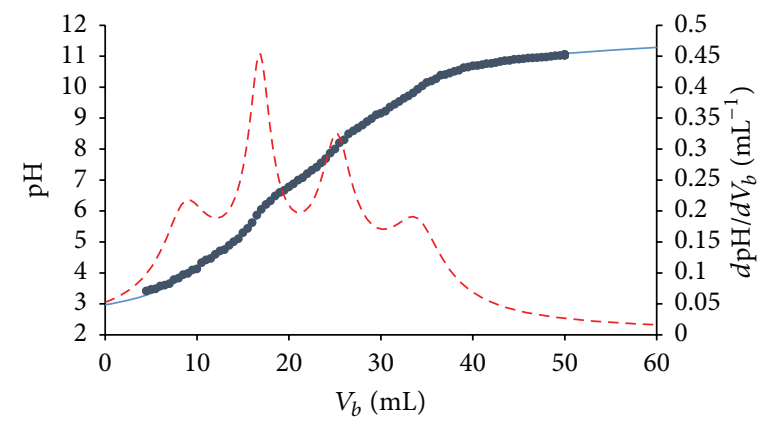

(a)

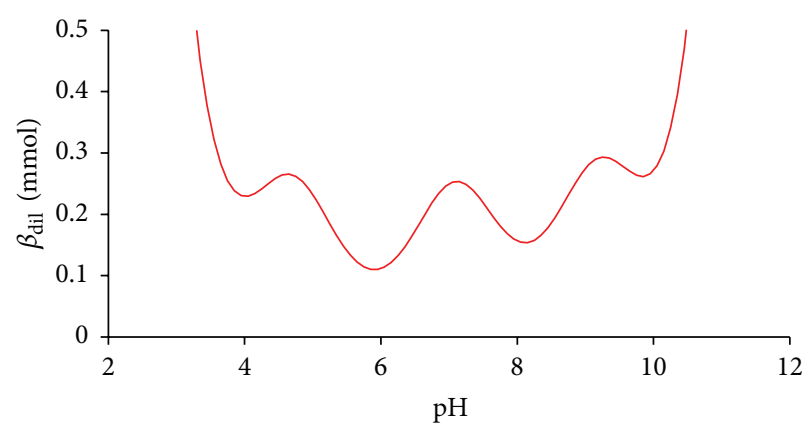

(b)

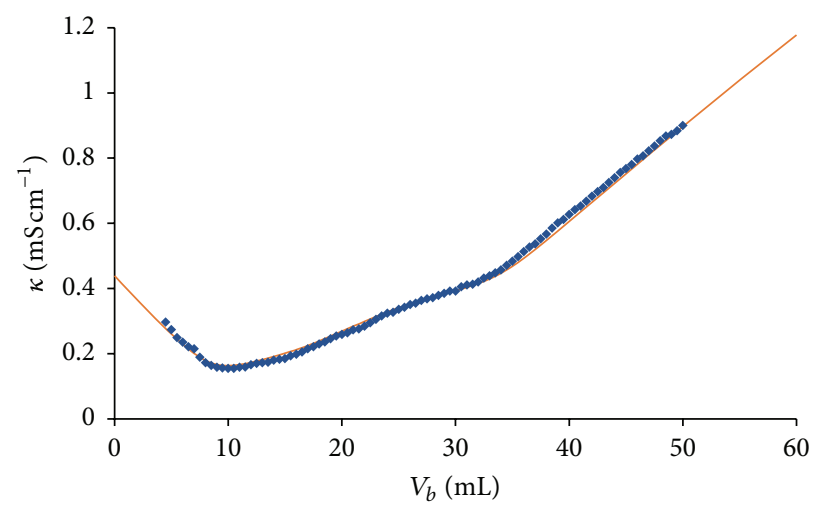

(c)

Figure 6: Titration plots of a Britton-Robinson solution, obtained after mixing $30.00 \mathrm{~mL}$ of a $\mathrm{CH}_{3} \mathrm{COOH} 0.015$ mol L ${ }^{-1}$ aqueous solution with $30.00 \mathrm{~mL}$ of a $\mathrm{H}_{3} \mathrm{BO}_{3} 0.015 \mathrm{~mol} \mathrm{~L}^{-1}$ aqueous solution, $30.00 \mathrm{~mL}$ aqueous solution of $\mathrm{H}_{3} \mathrm{PO}_{4} 0.015 \mathrm{~mol} \mathrm{~L}^{-1}$, and $260 \mathrm{~mL}$ water, titrated with $\mathrm{NaOH}$ at $0.050 \mathrm{~mol} \mathrm{~L}^{-1}$ concentration. (a) $\mathrm{pH}$-metric plots: the markers represent the experimental recordings obtained (corrected through the efficiency of the cell as indicated in Section 2). The solid line represents the plot $\mathrm{pH}=f\left(V_{b}\right)$ estimated (22) whereas the segmented line represents the $d \mathrm{pH} / d V_{b}=f^{\prime}\left(V_{b}\right) \approx \Delta \mathrm{pH} / \Delta V_{b}$, obtained from the fitted model. (b) Plot of buffer capacity with dilution $\left(\beta_{\text {dil }}\right)$, estimated as $\beta_{\text {dil }}=C_{b}\left(d V_{b} / d \mathrm{pH}\right) \approx C_{b}\left(\Delta V_{b} / \Delta \mathrm{pH}\right)$, as a function of $\mathrm{pH}$, for the Britton-Robinson solution. (c) Conductometric plot $\kappa=g\left(V_{b}\right)$. The markers represent the experimental points obtained and the solid line represents the estimated plot with (23).

In agreement with the results of the potentiometric titration, with the robust model and the maxima of the first derivative, the concentrations of each acid in the mix are $C_{o}=$ $[\text { Acetate }]_{\text {total }}=0.0012 \mathrm{M}, C_{1}=[\text { Borate }]_{\text {total }}=0.0013 \mathrm{M}$, and $C_{2}=[\text { Phosphate }]_{\text {total }}=0.0012 \mathrm{M}$.

The first derivative of the $\mathrm{pH}$-metric titration $d \mathrm{pH} / d V_{b}$ also allows determining the buffer capacity with dilution of the systems, since $\beta_{\mathrm{dil}}=C_{b}\left(d V_{b} / d \mathrm{pH}\right)$. This plot, which is presented in Figure 6(b), shows that, in effect, the amount of strong base or strong acid that the solution may spend at the minima is at least one-third of that from the maxima of the plot, in the 2 to 12 intervals, which is considered a universal buffer system.

3.3.3. Conductometric Titration. Figure 6(c) shows the conductometric titration of the acid mixture in the initial volume $\left(V_{o}\right)$ of $350.0 \mathrm{~mL}$. The robust model, even in this case, allows a good fit to the experimental results, using (15), (16), (21), (22), and (23), in spite of the fact that the experimental behavior is much more complicated in these Britton-Robinson solutions than in the previous cases. The part of the plot where the fit is not quite so good may be due to stirring problems in the cell (given that in this case the large cell was used, described in Section 2, because in this case the conductivity variations in the solution are smaller during the course of titration).

The plot $\kappa_{\text {corr }}=f\left(V_{b}\right)$ of this titration should lead to expecting four slope changes at the linear trends found in different regions of the plot, which relate the equivalence points that can be noted, which is why Figure 7 presents the comparison of the dilution-corrected conductometric plot and that without correction (Figure 7(a)), while Figure 7(b) presents the dilution-corrected conductometric plots, the experimental (markers) and the estimated with the robust model (solid line), as well as the first derivative of the plot with the estimated data (broken line). The uncertainty associated with measurements makes it more difficult to select the regions of the plot with linear tendency; hence the equivalence points become easier to see in the plot of the first derivative, in spite of the fact that there are four equivalence points of reactions at the quantitivity limit for their instrumental detection. The ancillary lines (broken) have been included in Figure 7(b) to emphasize the usefulness of the first derivative plot. The detection of the equivalence points is comparable to that of the potentiometric method, provided the plots of the derivatives are used in both cases. 


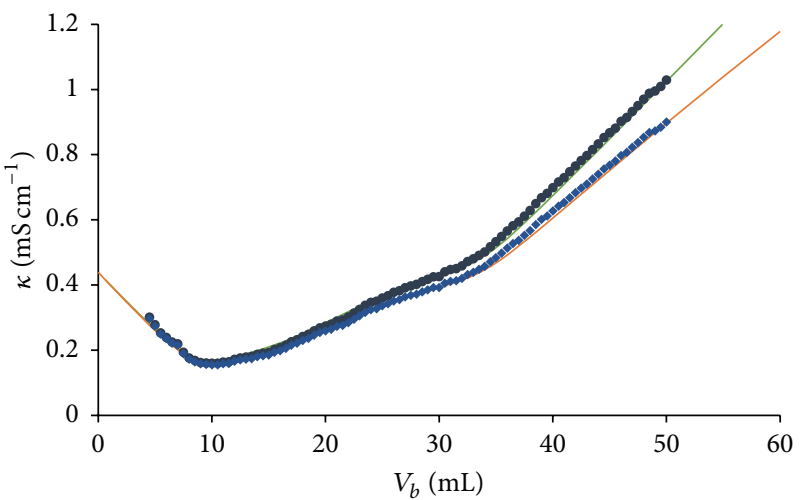

(a)

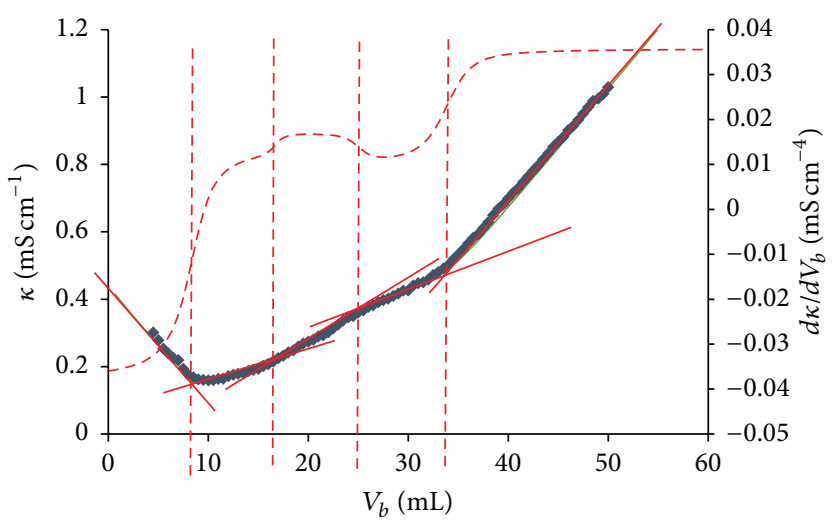

(b)

Figure 7: Plots of $\kappa$ and $\kappa_{\text {corr }}$ as a function of $V_{b}$ for the titration system stated in Figure 6 . (a) The plots of the system's conductivity and the corrected conductivity are different because of a large dilution during titration. (b) Plots $\kappa_{\text {corr }}=h\left(V_{b}\right)$ experimental (markers) and estimated through (23) and (3) (solid line) and its first derivative, $d \kappa_{\text {corr }} / d V_{b}=h^{\prime}\left(V_{b}\right) \approx \Delta \kappa_{\text {corr }} / \Delta V_{b}$ (segmented line). The thin solid lines are added to emphasize the linear trends in the conductivity curve while the broken lines are ancillary elements to emphasize that the slope changes must coincide for both graphical representations: $\kappa_{\text {corr }}$ and $d \kappa_{\text {corr }} / d V_{b}$.

\section{Conclusions}

This work presented a method to estimate conductometric plots during Brønsted acid-base titrations, with exactness and precision, applying a robust model to obtain $\mathrm{pH}$-metric plots, because the said model allows knowing the thermodynamic equilibrium conditions of all the species comprised in a given system, which makes it possible to determine any equilibrium property with which there is relation with its known composition.

The study of different cases showed that the exact estimation of the conductometric plot is possible, even during titrations of complicated mixtures, and that the fitting to the experimental results can be done through parameters already reported in the literature.

The conductometric study, supported with this robust estimation method, brings about information that it is not accessible from the $\mathrm{pH}$-metric study. Also, the estimated conductometric one, that fits adequately the experimental results, allows estimating its first derivative plot that is a valuable tool to detect the titration equivalence points.

The main advantage in having a robust model to estimate exactly the plots, either $\mathrm{pH}$-metric or conductometric, allows interpreting complicated systems and distinguishing the contributions from the different species of the system, for example, the buffer, at the $\mathrm{pH}$ or the conductivity of the system, whenever it is desired to characterize molecules like pharmaceuticals, additives, new materials precursors, and so forth. Several problems to apply the model that may be dealt with using the method presented here can be the characterization of polymers based on latex functionalized with acid or basic groups [5], the determination of wines acidity [7], or the characterization of the buffer capacity of universal buffers, like the Britton-Robinson [4], amongst others.

\section{Conflict of Interests}

The authors declare that there is no conflict of interests regarding the publication of this paper.

\section{Acknowledgment}

Norma Rodríguez-Laguna thanks CONACyT for the studentship to pursue postgraduate studies.

\section{References}

[1] I. N. Levine, Fisicoquímica, vol. 2, McGraw-Hill, Madrid, Spain, 5th edition, 2004.

[2] A. J. Bard and L. R. Faulkner, Electrochemical Methods: Fundamentals and Applications, John Wiley \& Sons, New York, NY, USA, 1980.

[3] C. J. M. Pingarrón, Química Electroanalítica. Fundamentos y Aplicaciones, Síntesis, Madrid, Spain, 2003.

[4] J. A. Dean, "Electrolytes, electromotive force, and chemical equilibrium," in Lange's Handbook of Chemistry, p. 8.113, McGraw-Hill, New York, NY, USA, 1999.

[5] J. Hen, "Determination of surface carboxyl groups in styrene/itaconic acid copolymer latexes," Journal of Colloid and Interface Science, vol. 49, no. 3, pp. 425-432, 1974.

[6] P. Brunatti and H. De Nápoli, “Titulaciones Conductimétricas," 2014, http://materias.fi.uba.ar/6305/tps.html.

[7] J. Darias-Martín, A. Socas-Hernández, and C. Díaz-Romero, "Comparative study of methods for determination of titrable acidity in wine," Journal of Food Composition and Analysis, vol. 16, no. 5, pp. 555-562, 2003.

[8] G. M. Fleck, Equilibrios en Disolución, Alhambra, Madrid, Spain, 1967.

[9] P. Tarapčik and E. Beinrohr, Implementation of a Universal Algorithm for $\mathrm{pH}$ Calculation into Spreadsheet and Its Use in 
Teaching in Analytical Chemistry, Faculty of Chemical and Food Technology STU, Bratislava, Slovakia, 2005.

[10] R. de Levie, "General expressions for acid-base titrations of arbitrary mixtures," Analytical Chemistry, vol. 68, no. 4, pp. 585590, 1996.

[11] R. Gutz, http://www2.iq.usp.br/docente/gutz/Curtipot_.html.

[12] C. E. Efstathiou, 2014, http://www.chem.uoa.gr/Applets/AppletTitration/Appl_Titration2.html.

[13] A. G. Asuero and T. Michalowski, "Comprehensive formulation of titration curves for complex acid-base systems and its analytical implications," Critical Reviews in Analytical Chemistry, vol. 41, no. 2, pp. 151-187, 2011.

[14] A. Rojas-Hernández, N. Rodríguez-Laguna, M. T. RamírezSilva, and R. Moya-Hernández, "Distribution diagrams and graphical methods to determine or to use the stoichiometric coefficients of acid-base and complexation reactions," in Stoichiometry and Research-The Importance of Quantity in Biomedicine, A. Innocenti, Ed., chapter 13, pp. 287-310, InTech, Rijeka, Croatia, 2012.

[15] N. Rodríguez-Laguna, A. Rojas-Hernández, and M. T. RamírezSilva, "Study and behavior of the buffer capacity of mixtures of species of a same protons poly-donor system," Educacion Quimica, vol. 25, no. 1, pp. 210-222, 2014 (Spanish).

[16] A. Rojas-Hernández, M. T. Ramírez-Silva, A. Galano, J. L. Córdova Frunz, and J. F. Pérez Arévalo, "Charlot's equation, and flood and gordus graphs," Educación química, vol. 21, no. 4, pp. 306-313, 2010 (Spanish).

[17] N. Rodríguez-Laguna, Theoretical contributions to the buffer capacity notion considering insoluble and polynuclear species [Ph.D. thesis], Universidad Autónoma Metropolitana-Iztapalapa, Mexico City, Mexico, 2015, (Spanish).

[18] D. C. Harris, Análisis Químico Cuantiativo, Reverté, Barcelona, Spain, 3rd edition, 2003.

[19] J. M. Islas-Martínez, D. Rodríguez-Barrientos, A. Galano et al., "Deprotonation mechanism of new antihypertensive piperidinylmethylphenols: a Combined Experimental and Theoretical Study," Journal of Physical Chemistry B, vol. 113, no. 34, pp. 11765-11774, 2009.

[20] I. Puigdomenech, Making Equilibrium Diagrams Using Sophisticated Algorithms (MEDUSA), 2014, http://www.kth.se/en/ che/medusa/downloads-1.386254. 

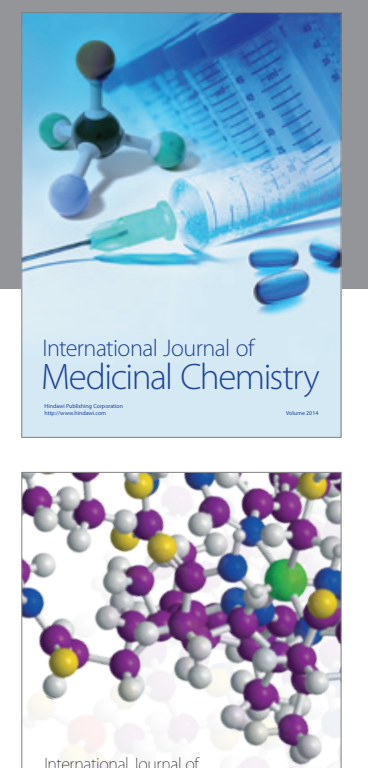

\section{Carbohydrate} Chemistry

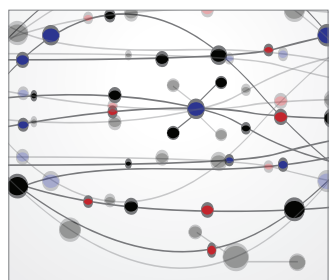

The Scientific World Journal
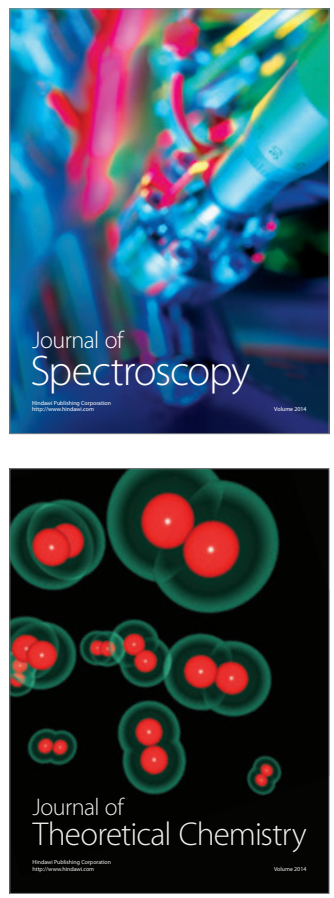
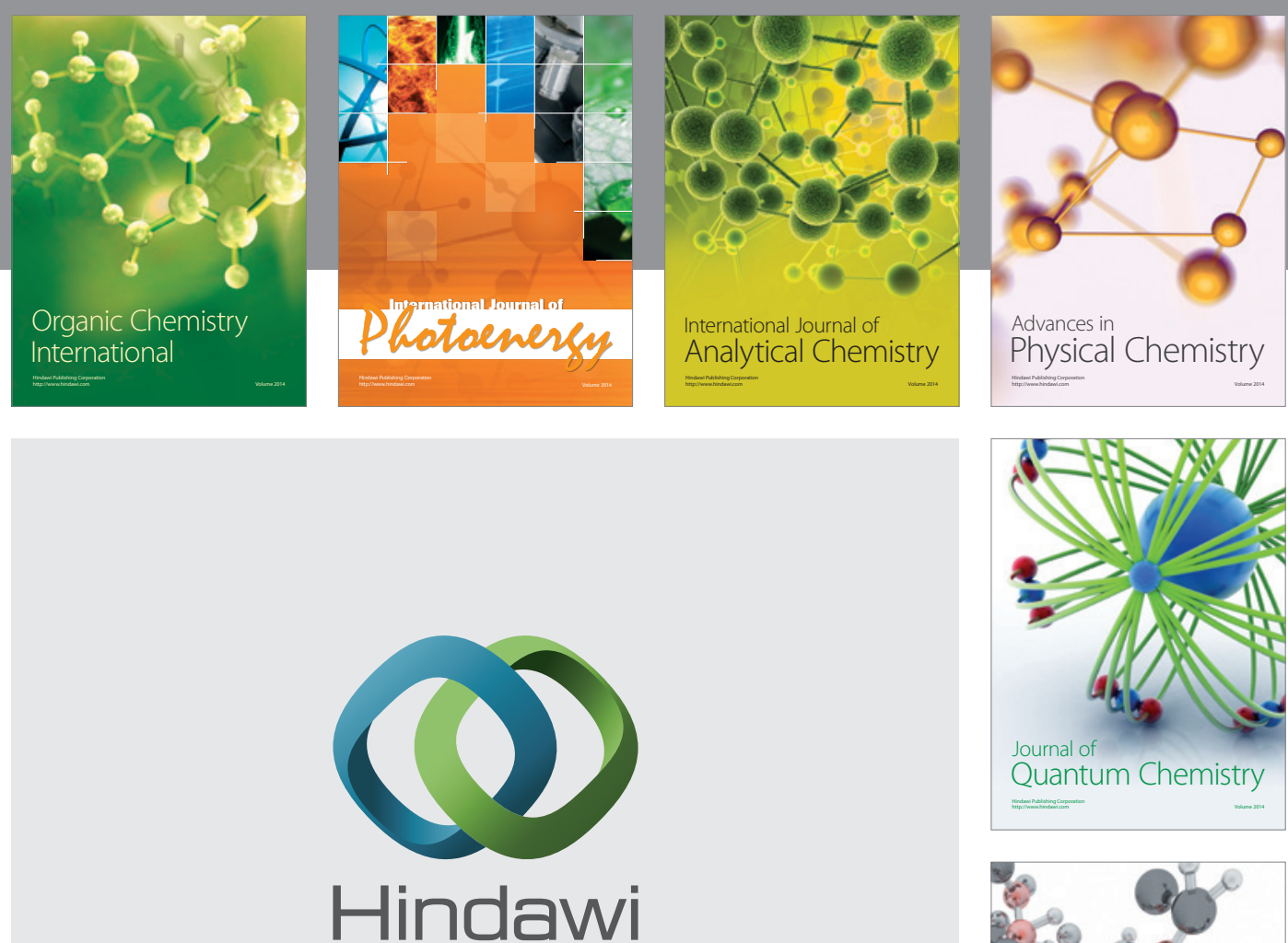

Submit your manuscripts at

http://www.hindawi.com

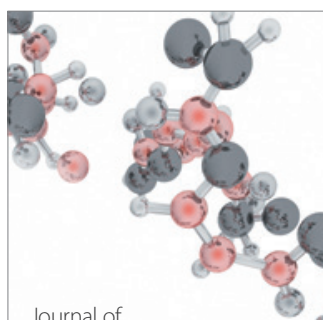

Analytical Methods

in Chemistry

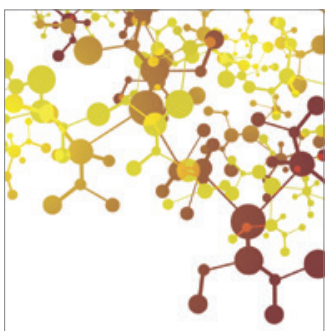

Journal of

Applied Chemistry

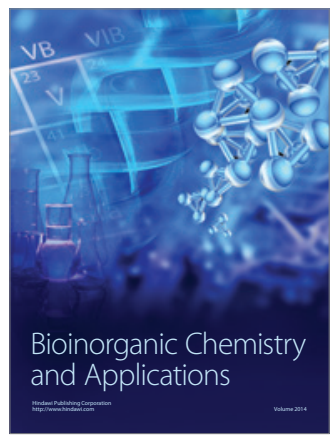

Inorganic Chemistry
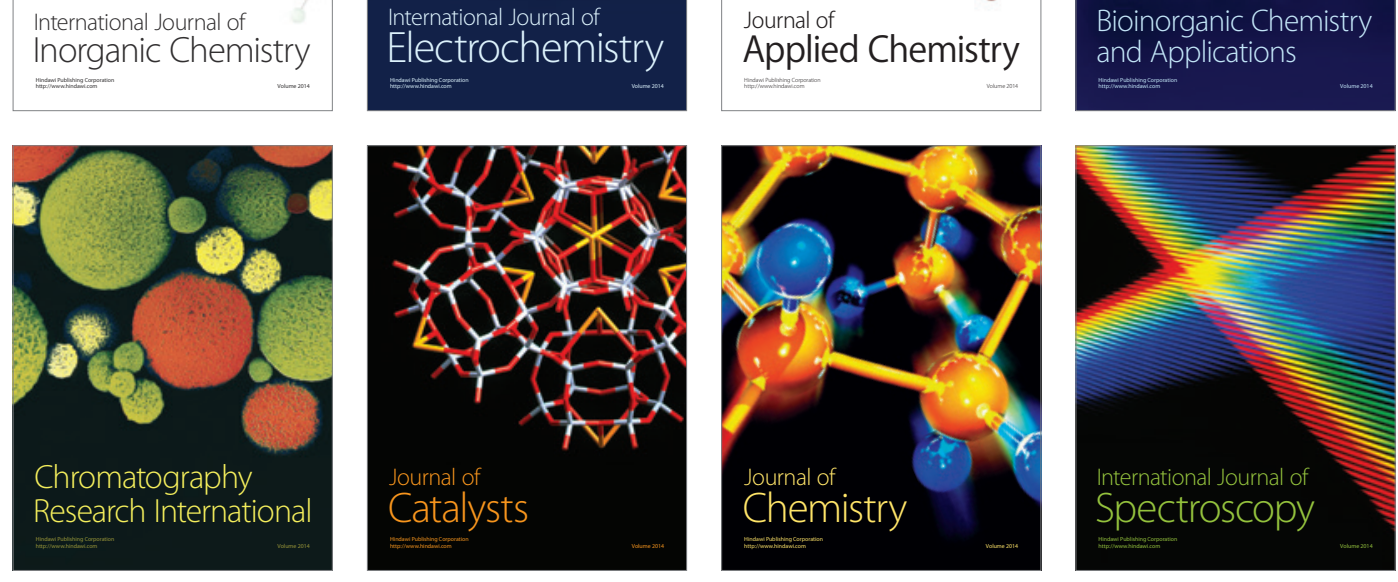